\title{
Review of the contemporary composer Guan Zhuang in Yunnan province
}

\author{
Ren Xiulei ${ }^{1, a}$, Xing Rong ${ }^{2, b}$ \\ ${ }^{1}$ Yunnan Qujing Normal University School of music and dance, Yunnan qujing, China, 655011 \\ ${ }^{2}$ Kun Ming University, Yunnan Kunming, China, 650214 \\ arenxiulei666@163.com, ${ }^{b}$ Xingrong650214@163.com
}

Keywords: Guan Zhuang; Music creation; A review of

\begin{abstract}
Yunnan has a variety of folk music, with the unique position of the art creation source. In China music, be too numerous to enumerate the Yunnan folk music works with elements of creation. As the first generation of Yunnan, the composer of the first generation of, in Yunnan rich folk music of the soil in the hard work of more than half a century, creating a large number of music works, shaping a variety of styles, different forms of national music image, which involves a wide range of genres, the theme of the foundation for the Yunnan contemporary music, Yunnan folk music made a contribution to promote the development of Yunnan contemporary music. In this paper, we review the history of Yunnan music creation, and comment on the music creation idea, music style, music characteristic, and its contribution to Yunnan's contemporary music creation.
\end{abstract}

\section{Introduction}

Yunnan mud makes him sprout green leaves of the first piece of art, is Yunnan's first music phone folks taught him the bird.

- Guan Zhuang

A blood that flowed in the Central Plains, the surging Yellow River shouting young man in in the 1950 of the 20th century, set foot on this beautiful piece of land in Yunnan.He was attracted by the beauty of Yunnan, was moved by funky mellow folk in Yunnan, and extricate themselves bogged down in Yunnan and colorful folk music, his youth and life, art delivery in this red makes his frenzied land, he is to new China's first generation of the fame of the Miao nationality folk song composer and contemporary iconic composers - Guan Zhuang in Yunnan province.

Guan Zhuang, Henan Kaifeng was born in 1930 in a very artistic family, his father was an art lover, enthusiastic about painting and drama.Guan Zhuang, by his father's influence, for his hometown had a keen interest in Opera, and in her spare time, he sang opera scripts, memorize memory board, national musical instruments such as erhu and banhu, folk music is subconsciously in Guan Zhuang heart took root.Guan Zhuang, glorious army at age 19, and participated in the IV Corps of the PLA art troupe, was soon transferred 13 army ensemble, 13 army art troupe, Guan Zhuang, master Yun, Wu Haoye studying music composition and violin, first contact the formal knowledge of music.But two teachers imparting knowledge, fall far short of Guan Zhuang's thirst for musical knowledge, he bought a lot of music books through various channels, and includes works of harmony, counterpoint, analysis, assiduous self-study in their spare time, final structure and perfect their knowledge of composition architecture The same year, the whirlwind of the revolution brought checks to the Township of song and dance, Yunnan, he was rich ethnic customs and rustic culture in Yunnan personality attracted and began greedily sucked milk of Yunnan ethnic folk music, opening his Yunnan music course.

\section{The cornerstone of national music, wide draw on concepts of music creation}

People, especially the artists who must have root!At your doorstep ... ....--Guan Zhuang

Guan Zhuang have their own distinct musical ideas.He said at the conclusion of his course was moved: no root is pathetic!But there aims to fill the branches, for the open sky, for the colorful life, 
bear fruit.This is innovation, innovation, innovation!Otherwise, the "root" will lose the meaning of existence.[1] Thus, the Guan Zhuang music from beginning to end, rooted in folk music at broad and far-reaching, and from time to time to learn Chinese and foreign excellent music, making their music varied and unique.

This is Guan Zhuang creative musical works can be verified.As his fame-the female lead singer and the chorus of the Miao nationality folk song (Pan Zhen words), the creative inspiration and works using folk music material is derived from an in-depth experience of country life.A spring of 1953, and Guan Zhuang, and fellow artists knapsack on his back and fiddle, on the Red River of the trip to collect folk songs.In Hmong cottage in, Guan Zhuang see has people turn Hou of joy, Feel to "liberation has" "happiness is party to of" "to with party to created more better of tomorrow" of all people of voice and times beat of pulse, he of heart was strongly to impact has, time, inside was "to folk songs learning, wrote out people voice, wrote a support new life joy Carol" of strongly creation desire full with [2].Guan Zhuang, are worried about how to write, a simple and soulful song coming from the open window, a Miao Girl sang sweet and simple ballads on the way in cattle and Guan Zhuang bursts of inspiration, wrote, all completed his famous work of the Miao nationality folk song.Songs with strong ethnic style, the distinctive artistic personality, strong emotions prevalent in the country.In led part composer to express Miao small girl singing liberation joy of mood, South Jinping of Hmong folk songs for based, rubbing into has Guizhou Hmong, and buyi folk songs of some factors, Melody beautiful soft, even jumping light of melody line also to small jumped mainly, and tightly caught has Hmong folk songs by unique of sound group for, makes songs of melody has rich of Hmong flavor and cheerful, and expressing of youth breath.Mixed Chorus part, to further emphasize and render jubilant Ode to the warm atmosphere, composer consciously adopted ethnic dance rhythms, and stands in contrast to the singing part.Song is unique composer broke in the general sense to work ended in principle on the main chords, song sound new landed on the Gong sound three chord in second inversion.Throughout The song the adjustable layout, composers, starting from the charming and beautiful angle-adjustable, with the song emotional needs, has developed into a warm and pleasant mode of levy, the whole works in the pentatonic scale angle and features two modes Alternately, natural and appropriate, make it a refreshing aesthetic sense of hearing. The success of this song, and Guan Zhuang, life and creation, cultural tradition and the spirit of the age, ethnic styles and modern law, set a series of thinking on the issue.He wrote in the creation of the Miao nationality folk song: the melody is not artificially glossing over, but real-life;Freehand is not a political slogan, but a sentiment voiced;Not without groaning, but the voices of the masses![3] similar music abound in the Guan Zhuang music, such as songs of the my little black horse, children's suite for reading and music, dance music of happy water festival of the Jingpo knife dance, light music, and so on.Thus, Guan Zhuang, the cornerstone of national music, Guang JI gambling in music theory in music has been fully confirmed.

\section{Many folk music elements and combination of music styles and characteristics}

My song is the wave of folk music in the vast ocean, cheering, shouting, splash ......

--Guan Zhuang

Guan Zhuang on the occasion of the founding of new China came to Yunnan, all literary and art workers should play their Socialist enthusiasm as people should "voice" or "trustee" to pursue their artistic work.During this period, songs are still in the creation of all kinds of music's most influential and created the largest number of an area, almost all the famous musicians and musicians are involved in the creation of this kind of music, and Guan Zhuang also ranks.Guan Zhuang, an extremely broad field of music creation, included vocal music, instrumental music, dance music, music for film and television genres, formed a diverse genres, styles, and has a rich folk music musical pattern. Since 1950, and Guan Zhuang music works often in the songs and the people's Liberation Army song, song Yunling and other publications published and performed on stage and radio.It is representative of the vocal work of the Miao nationality folk song, ' my little black horse ', the March ballad, Yi girls sub yisuo ', ' sunflower sunny opening and the a string of waves of a song already recorded as record or tape release.The creation of the au Lac, au Lac, such as dance, music, 
and when five or six times in the last century caused a strong reaction, creating a dance music of Yunnan precedent.Tearful Burmese dance drama creation of GUI, in the historical context, are a difficult work.In addition, In addition, orchestral suite of the Yu Han Guan Zhuang creation, as well as the scenery over here is good, the spot color, and the one-inch instructors, the respondents with blood, and the special gardener, does not put out the fireplace and other film and television music, each in various artistic fields for the earlier attempts.

The vocal era of many folk music elements and is used in conjunction. Guan Zhuang, the songs of the genre and subject matter are involved is extremely rich, choruses, duets, solos, and diversification of subject, description of folk customs, labor, there is praise, this genre very closely to the pulse of the times.

Guan Zhuang, 1964 by the song of the Buttercup open Sun (female Duet), Jinghong, Xishuangbanna Changha is chosen national tone as the material development of singing creations, described the frontier after the founding of great change in appearance, praising the people of frontier love of his country. While creation of the Yi girls sub yisuo (female chorus) is used in sharp tones to creative development of the Yi people.Soprano solo tune the a string of waves of a song was written in in the 1970 of the 20th century, this song uses the Lahu nationality folk music, composer of Lahu people of the big jump intervals become the national style and color with a coloratura soprano.On the accompaniment of the song, using the flute and harp cadenza imitating shows irrigation lahushan area, brought about by the development of agricultural drainage water flowing, flowers and a happy happy harvest scenes. Such as Dai tone creation of baritone solo of the elephant-foot drum and Peacock Dance, happy and full of charm of the Dai nationality dance, show Peacock and elephant-foot drum rhythm;Male lead singer and the chorus of the Red land, red Camellia, Honghe Prefecture of Yi tones of creation, painted a red Camellia of Yunnan red land, Yunling plateau features, expression of Yunnan people's love, feelings of loving the motherland, has a unique lyrical style and strong momentum; Girl solo of the Manchu girl good airflow, created in 1995, material from the original lyrics to the Manchu nationality writing, the performance of the Manchu girl snow games in the Festival's graceful and beautiful colorful charm.Boys and girls singing of the cangshan mountain and erhai Lake in antiphonal style, created in 1991, material from the original composers of Bai folk songs, loud, wild mountain atmosphere, reflects the joy of the Bai people's pursuit of a new life. Music using the above Yunnan local folk music as source material, expresses the frontier on the new democratic Government of the people's birth, the great feeling of celebration and love of the motherland, and has a strong sense of the times and mass.

Guan Zhuang, was also a cause of concern for children composers, he is good with pop music vocabulary, consistent with the child's psychological characteristics of music language children's vocal works.Among them, the most representative non-choral Suite belong to reading music.This suite of creation originates from the summer of 1994, project hope with its powerful cohesion and solidarity, launched project hope in the country $1+1$ of student activities, he and songwriter Cao Yongqing, with common aspirations, dedicated a love for project hope.Choral Suite made up of seven songs, creators consider the audience for this music, especially considering that can make children sing in remote mountainous areas, often used in creative technology, selected tonality, melody and rhythm of writing, also as far as possible simplification and popularization. Works by ordering song reading music, reading and the mother, grandmother hypothesis and the village children into school, the dialogue between child and mother ', ' I'm going to read to achieve, the mountains outside listening, of the country to create a brilliant seven parts. This song has a complete set of images, namely frontier children yearning for reading, entrusted to the elders of commitment, grew up to become the vision, vision of glory for the motherland of the concentrated expression.Composers use song information in the form of project hope, great times and mass.Entire set of melodic, clear theme, image, language capable, lively style, fully embodied the era's emotions and feelings of sincere support of the people of hope.Choral songs of the book of creation, is a common sense, easy to understand language, distinct musical image, flowing melody line of the song, rich and full of power harmonic structure, creating a high quality vocal work.[4] the whole song lyrics and simple, flowing melodic, light and lively rhythm, in line with the 
language features of children's speech short.Sixth song for the motherland in the works to create a musical image of glory is a suite of high level.This song is an ode to a typical March, momentum of the brilliant, the composer used a variety of musical instruments, and the impulse of accompaniment, full and rich harmony, passion and glorious melody, elevate the overall image of China children and teenagers ' to a new height, and depth to express the children's vision of the future.

Guan Zhuang and three children work is also very unique.The Ava juveniles, respectively, and the beautiful flowers, the colors of sunlight. The three tracks not only have the above characteristics of children's songs, on the application of folk music is also a high stress. The AVA is a prelude of the juvenile from the Wa people's wooden drum style has a strong start, followed by a sharp and passionate of dance melodies, showing Ava juvenile bravery, diligence, wisdom of spirit.The song original creators basically maintained the WA folk song style, as well as the melody and rhythm of for rich WA features are on full display. The colorful Jingpo melody notes of the melody of the Sun tunnel and elephant-foot drum and small cymbals hit very full of rhythm of the dance of the Jingpo ethnic group features, deep portrays the spirit of the new young pioneers of spirits in the minority areas.

Instrumental music era of many folk music elements and is used in conjunction. Located in China's Southwest Yunnan province is a beautiful and magical place, "a different mountain, ten different day."In the laterite plateau, breeds 26 self people.Ancient people used the "colorful Yunnan" to yaozhi this mysterious cloud Ridge plateau.Yunnan customs of the ethnic variety is a living history museum.Each people's clothing, food, housing, transportation and marriage, funerals, births, code, etiquette, language, writing, totems, religions, taboos, aesthetic all knots for a variety of cultural links.Naxi Dongba culture and Dali Bai people's culture, the Dai's pattra-leaf culture and Yi beima culture ... ... Water-splashing Festival, Arbor Festival, Flower Festival, the provincial government based upon a unique, deep and deep.Along with these festivals, the ceremony was rich and full feature music and dance.Therefore, Yunnan is known as "home of song and dance of the ocean".Generations of people invested in the whole meaning of life is to a wonderful song and mysterious dance, carrying them for generations and the bucket, bucket, and life history information, is their history, life, and spirit of the Crystal.These colorful folk music, music provides an inexhaustible source of Yunnan.Guan Zhuang in dance music, and music for film and television have made great contributions in the field, Yunnan dance music and the development of film and television music drawing on the event in a pen.Its major National Ballet music to the tearful Myanmar GUI, happy Songkran and other musical works, exudes the fragrance of the Earth, with strong ethnic flavor.In particular his dance music works, the big music, au Lac, on the first stage of this work was the first to introduce JINO musical works, it lets people heard the voice of the nation for the first time. JINO is the Alpine nation, melodic breath of lack of stretch, so composers only selected nationality folk song in the interval of a minor seven jumped into the most characteristic, beautiful Southern folk song technique of broad melody and decorative touches, makes beautiful music conveys passion, stretch, and the aesthetic experience.

Synthesis, characteristics and Guan Zhuang's music style can be summarized as the following:

(1)Strong sense.The early days, the young Republic, like the rising sun shines, one filled with hope for the future, under the leadership of the Communist Party of China, and confidently build their country.Arts community is flourishing prosperity Guan Zhuang, song of creation is in the background, tightly close to life, reflecting reality, its basic tone clear healthy, vigorous, encouraged people to work hard and aggressive.

(2)Strong national style.Music must have Chinese music characteristics and forms of folk music, will have a wide range of audiences.Guan Zhuang, convinced he was attracted by the colorful Yunnan ethnic and folk music and ecstatic flutter into the folk music of the vast water, absorb nutrients to enrich their music works.In his music, all fed to them by the show folk music and effects.As the great Russia composers Glinka said: "the composer's creation based on people's music, making music people, composer was just to make it."

(3)The new musical language.Innovation, based on the folk music, succession development, innovation is pursued by the composer.Guan Zhuang, based on the absorption of original folk music, 
melody, rhythm, harmony, music, tone, and other aspects of a new exploration of innovation, their music took on a strong ethnic music styles and aesthetic of the new hearing.

(4)Bright mass.Popular melodies to sing, and daily life, suitable for performances and for pleasure, easy accepts the broad masses and sings.

\section{Guan Zhuang's contribution to the music of Yunnan--Yunnan folk music evangelist, founder of contemporary music in Yunnan.}

Recalling nearly 50 years of music in Yunnan, Yunnan, we can see the numerous outstanding musical work in front of us.In particular, older musicians like Guan Zhuang, for the spread and inheritance of Yunnan folk music to create infinite possibilities. Guan Zhuang in the construction of a second home is performing an act of duty posts, contributed to the construction and development of music culture in Yunnan, has played a leading role.He used music to express and convey their own and the voice of the times, in the creation of his music, full of his experience of life, the pursuit of music, it is this pursuit made Guan Zhuang, song writing, always flowing with beautiful, fresh and original melodies.For many years, Guan Zhuang, almost went to cloud Ridge Highlands, he left music in the Dai bamboo House, Miao fireplace recorded folk songs, Vasant lane shed sweat, in Aini tea garden collection sweet ... ... In his works, all reflecting the beautiful mountains of the frontier, the nation's customs practices.As an army of writers and artists, and Guan Zhuang people soldiers sing, reflects the army as their sacred duty.He made many deep in Yunnan border frontline interview hero in Vietnam fought back in self-defence, Frontier battle deeds, created a number of thought-provoking works.Such a spirit worthy of our many musicians and respected, was also his relentless, tireless spirit we Yunnan development and heritage of folk music, to let more people understand and fall in love with ethnic music. There is no doubt that Guan Zhuang, as representative of the first generation of strong contemporary composer in Yunnan, one of his music has not only laid the groundwork for contemporary musical creation in Yunnan, but also promote the pace of contemporary musical creation in Yunnan, Yunnan post music provides a reference model for Chinese lessons.

\section{References}

[1] D.H. Zhang. Composer Guan Zhuang's "roots". The people's Liberation Army song, 1986, (6): 3.

[2] X. Ding.This is a world of twinkling stars.Defence literature, 1983, (7) 8.

[3] X.P. Yang.Green Clay friendship.East landing times, 1997, (4): 15.

[4] waiting red cloud. Music in love with melody-and Guan Zhuang, choral songs of hope ' book of children's songs, such as impressions on.Internal reference. 